\title{
Media Usage and Consumption Practice in Shopping Malls Among Female Youth in Modern Thai Society
}

\author{
KANGWAN FONGKAEW \\ Department of Communication Arts, Faculty of Humanities and Social Sciences \\ Burapha University, Chonburi, Thailand \\ email: kangwan@buu.ac.th
}

\begin{abstract}
This paper presents the data derived from the longitudinal ethnographic study on media usage and consumption practice in shopping malls as everyday life practices among female youth in a modern society of Chiang Mai, Northern Thailand, which contributed to their distinctive sexual identity construction and expression. Applying Bourdieu's theory of cultural capital and Friske's idea on tactical practice, this paper revealed that the various tactics female youth employed in shopping malls were to express their distinctions from other youth groups belonged to lower classes, as well as to negotiate mechanisms of dominant school and state controls that aimed to regulate their sexual and cultural practices. Female youth in modern society were not only proper "consumers" but also "users" of shopping malls in modern Thai society. Their media usage and consumption practice sought to send the messages that they were the creators of their own selves.
\end{abstract}

Keywords: Youth, Media, Consumption, Shopping Mall, Thailand

\section{Introduction}

In Chiang Mai, a famous tourist area of Thailand, global flows of people, capital and information have brought rapid changes and expansions into the city-physically, economically and socially. Changes in city planning and urban space development in Chiang Mai have led to an increased number of its new residents. This has lead to dramatic changes in city dweller's experiences, ways of living and thinking. This is especially true among young people who form and operate their own subcultural lifestyles (Cohen, 2009; Fongkaew, 2007; Michinobu, 2005).

Shopping malls, which are considered as one of the indications of moden society, are not merely an empty stage but a structured commercial zone dedicated to motivating desires and identifications. Shopping malls allow a venue away from home and school that provides a space for freedom for youth and host a variety of expressions of identity (Wilson, 2004). Shopping malls then become a site that provides an opportunity for young people to present themselves in a particular way; and as such they become consumption and sexualizing spaces for youth to experiment and complete their selves and negotiate any control mechanisms through consumption practices and spaces unitizations (Khosravi, 2008).

According to the context mentioned above, this paper aims to show that, amongst the transformation of Chaiang Mai to a modern society, female youth in this city used the 'social weapon' (Bourdieu, 1984) through their media usage and consumption practices to identify themselves while comparing to other groups. At the same time, those practices were also the ways they negotiated and contested various dominating powers which imposed on them (Fiske, 1989). The results of this paper highlight the profound influence of global consumerism over the formation of female youth culture and identity in modern Thai society.

\section{Applying Ethnographic Methodology Among Female Youth in Shopping Malls}

This five-year-ethnographic research was conducted between June 2009 and April

Received: July 18, 2017, Revision: October 07, 2017, Accepted: December 14, 2017

Print ISSN: 0215-8175; Online ISSN: 2303-2499. DOI: http://dx.doi.org/10.29313/mimbar.v33i2.2716.399-407

Accredited B based on the decree No.040/P/2014, valid on February, 18, 2014 until February, 18, 2019. Indexed by DOAJ, Sinta, IPI 
2014. A group of thirteen female aged 18-21 years agreed to be participants for the study. The researcher first began his fieldwork in one public school located in an urban area. After submitting an official letter from the Faculty of Social Sciences at Chiang Mai University to the school administration, approval was obtained and preliminary fieldwork was carried out from June 2009 to March 2010. The ethnographic method was conducted during the period April 2010 to April 2014. The research participants were the students in the researcher's class when they were studying in their last year of high school and then transitioning to various universities in Chiang Mai city.

The researcher spent time to accompany them to several places, especially shopping malls Chiang Mai. Participant observation and in-depth interviews were conducted with all participants. All research participants were assured of their anonymity and confidentiality. Pseudonymous were assigned in this paper instead of their real names.

This paper exclusively focuses on female youth's everyday life media usage and consumption practices in shopping malls which contributed to their distinctive class and sexual identity construction and expression. The researcher investigated how the female youth group members constructed their distinctive sexual identity against the Other, called sakoy, a reference to what the research participants perceived as 'working class and backward' young women groups in urban Chiang Mai society. In the meantime, their media usage and consumption practice in shopping malls were also done to negotiate mechanisms of dominant school and state controls that imposed on them in everyday life basis.

Bourdieu's theory of cultural capital and Friske's idea on tactical practice were applied in this study. According to Bourdieu (ibid) the objects of consumer choice reflect a symbolic hierarchy that is determined and maintained by the socially domination to enforce their distance or distinction from other classes of society. Appropriating Bourdieu's idea, taste becomes a social weapon that defines and marks off the high from the low, the sacred from the profane, and the legitimate from the illegitimate. Therefore, this paper shows that research participants used the cultural capital to identify themselves to be 'higher-class' comparing to sakoy. Through various forms of media utilization and cultural commodities consumption, the girl group members always compared themselves as having better taste and being higher-class to other youth groups. Meanwhile, Friske (ibid) explains that those practices were also the ways they negotiated and contested various dominating powers, such as school, family and the state, which imposed on them. For the girls, moreover, media and cultural commodities appealed in some ways to them. They showed an ability to modify the resources made available to them depending on how it is used and how it is interpreted These practices can serve the interests of the girls to achieve a productive pleasure by utilizing them in alternative ways - to send a message of evasion or even resistance that they are not conformists to mainstream standards.

\section{"'Cen' is for Sakoy and 'Ro' is for Higher Class People Like Us": How Female Youth Differentiate Between Different Classes of Shopping Malls}

During the researcher was conducting a fieldwork, one of the research participants shared a topic namely 'Certain Stories about Chiang Mai You May Not Know' posted on www.pantip.com, one of the most popular web-boards in Thailand. This post presented contemporary information widely known among local youth in Chiang Mai but was unknown to outsiders. It described the terms 'saap' (for men) and 'sakoy' (for women). Both of them referred to working-class youth in urban Chiang Mai society who are supposed to be 'local' (i.e. not 'inter'[national]) and backward; and linked these to two major shopping malls, Cen and Ro, where were widely known among young people in Chiang Mai. These two malls were functioned as the social arenas for two opposing classes of youth:

\footnotetext{
'Saap' and 'sakoy' rarely go to Mall $A$ [anonymous].
}

There are a lot of gay and lesbian [toms and dees] couples hanging out at Mall $A$.

'Saap' and 'sakoy' are mostly found at Mall B [anonymous].

Chiang Mai local people call Mall B 'Cen.' Meanwhile, Mall A is called 'Ro.'

Keep in mind... So you [outsiders] can call them correctly [while visiting Chiang Mai].

According to Wilson (2004), shopping complexes and department stores generally target specific class ranges of consumers. In Chiang Mai, apart from five major department stores located in downtown, Cen and Ro were the two major places where Chiang 
Mai youth usually gathered after school and during weekends; some of them were also found skipping classes to spend time at these two shopping malls during school hours. Ro was recognized among local young people as a place for youth who were 'hi-so noi' (a bit high-class)while Cen was well-known as a space for an opposite group of lower or working class youth groups called 'saap' for male and 'sakoy' for female, as stated above.

\section{Consumption Practices Among 'Sakoy' (Working-Class Female Youth) Groups}

As a way to distinguish between different social classes such as the northern female youth who belonged to 'hi-so noi' and'sakoy' groups, Bourdieu offers his idea of 'cultural capital.' According to this concept, knowledge gained through education and social origin grant a person's social status. Cultural capital plays an important role in a system of distinction whereby one's personal taste corresponds with one's upbringing, education and class (Bourdieu, ibid). To understand similar social hierarchies that are formed within northern Thai youth culture, Cohen found that class indeed acts as an important measure of social distinction between groups among young Thais. It is especially evident through the overt distinction in 'rural' and 'urban' cultures and people that are made by Thai youth, which in Thailand is also often a strong signifier of class. For young Thais, one's status within the Thai youth hierarchy is determined by a combination of style, leisure activities and class (Cohen, ibid).

The researcher often accompanied research participants to shopping malls. They preferred to spend their leisure times at $R o$ rather than Cen since, according to Kim, they liked to see themselves as "a bit high class" (pen phuak hi class noi). One of the main factors why they considered themselves as such was due to their education and the relatively prestigious school they attended. Research participants explained to the researcher that since their school was located in the same area of vocational schools, they learned that they had different styles and tastes from those vocational students. Kim explained: "Students in my school and those students in vocational schools have different ways of thinking (wii tee kid tang kun)." (in-depth interview, 17 September 2013) To understand the term 'different ways of thinking' between high school students and vocational school students, while accompanying research participants to shopping malls, the researcher usually asked them to explain the characteristics of 'sakoy' and how those sakoy group had different ways of thinking from them.

After graduated high school, Kim was taking care of her father's coffee shop business at the basement of Cen, one of the major spaces were sakoy congregated. While research participants preferred going to Ro, Kim's coffee shop at Cen basement however later became like a meeting place for research participants studying in various universities. "It's like a ghetto. If Kim doesn't open a coffee shop and I have to meet you guys here, I'd never come to this place. It's very old. I used to watch a movie at the cinema up there. It was very cheap but very few people went there; very haunted. I saw a rat running passing me. Soooo disgusting!"(in-depth interview, 5 Febuary 2014): Mary complained about Cen with the girl group members while various groups of sakoy were walking passed the coffee shop. "Piek" (gossiping about/ critiquing) sakoy girls who were passing by the coffee shop became one of the favorite activities among the girl group members. Through this activity I also learned what Kim had meant when she said that sakoy had different ways of thinking from the girls in their own group.

At Cen, most sakoy usually assembled at the basement floor around the area of the mall's back entrance since there was a private motorcycle park available there. Working class youth usually rode motorcycles, while higherclass youth mostly drove cars and therefore used the car-park entrance. In front of the back entrance outside the mall, there were many food stalls selling food and drinks that were cheaper compared to those available inside the mall. Walking in the mall's back entrance, there were cheap karaoke machines and game booths, as well as clothes, shoes, and accessories shops along the way at the area that provided merchandises of lower quality and price than those sold inside the mall. These areas were packed with various working-class youth groups after school hours and during weekends. After Kim had been working at her coffee shop for a while, she talked about her observations on sakoy around that area that: "Those sakoy usually come to gather here. They don't do anything, just sit together in small groups, chat, and buy cheap food and drinks that they share with each other. They come looking for 'saap'. 
And the 'saap' try to show off by smoking. When they skip schools to gather here during study hours, I see the officials come down here to chase them away (laughs)" (in-depth interview, 5 Febuary 2014).

Having visited Kim's coffee shop more often, the researcher could notice some sakoy gathering around the area who showed up in their school uniforms or school sport uniforms that indicated they were studying in vocational schools or in what research participants considered lower-class schools. Their uniforms were adapted according to international fashion trends but the ways that styles appropriated by sakoy were always looked down on and made fun of among research participants, who considered sakoy to have the 'wrong taste,' partly because of their use of cheap accessory items. For example, Kim pointed me to see a group of female vocational students in their school uniform wearing their socks up to middle of their lower legs level, which were higher than usual many times. Kim teased them during the interview that:

"Look at those socks! They tried to imitate the Japanese school uniform but they make it look 'local' (baan) since everyone knows that those cheap socks might be bought from a local fair market somewhere. And you see that Japanese students wear their socks up to knee levels but these sakoy wear those cheap socks merely up to the middle of lower legs level. And wearing socks at that high level doesn't go along well with their uniform at all. That looks so cheap and ridiculous! (laughs)" (in-depth interview, 5 Febuary 2014)

Other 'unique' characteristics of sakoy were their hairstyles and hair colors. Sakoy tried to imitate hairstyles of celebrities who were popular at particular period of time. During a fieldwork, the hairstyle of one of the most popular Thai pop rock vocalists, $\mathrm{Da}$ Endorphin, was being appropriated among sakoy at that time. Her unique fashion and hairstyle became an inspiration for most sakoy in Chiang Mai, especially her unevenly sliced hairstyle from front to back.

Jill gave more information about the hairstyle of the sakoy imitated from $\mathrm{Da}$ Endorphin's. Since female students were required to tire up all of their hair properly while at school, having their hair sliced and bangs were then not allowed. Therefore, appropriating this particular hairstyle can be described as a tactic to contest school regulations. When being approached by teachers or school authorities, they could spend a very short period of time to tie up their sliced hair and bangs so as to be in line with the school regulations. Some sakoy also had their hair colored but since they usually had little budget, they would color their hair by themselves using cheap hair dyes, rather than have it done by professional hair stylists. The ways their hair colors and hair-do turned out was therefore made fun of as 'low-class'.

During weekend, sakoy showed up at Cen wearing cheap tight-fitting t-shirts, short pants and rubber slippers, which was called 'sakoy fashion' by the members of the girl group. Research participants enjoyed teasing and joking about sakoy for having dark skin, big-boned legs, as well as spots, scars, and cellulite visible on their legs, as illustrated by Amy that: "They might think that the shorter pants they wear, the sexier they are. But in reality, their cellulite and spotted darkskinned legs totally turn guys off! (laughs)" (in-depth interview, 5 Febuary 2014).

Regarding accessories, sakoy used relatively cheap handbags, necklaces, rings and bracelets, which research participants estimated might not cost more than 199 baht each, and which could be bought at any local market, temple fair market or shop around the Cen basement area. Most sakoy also had multiple piercings, especially on their ears. Some of them had more piercings on their navels, eyebrows or tongues. Those who had multiple piercings were teased by research participants for having bad taste, as they were seen as being too extreme and wearing too many earrings that were cheap and did not match together in terms of style.

Kim added that a little towel of particular brands was another accessory that was popular among sakoy at that particular period of time. This little towel fashion was first initiated among schoolgirls in high-class private schools in Chiang Mai. The little towel was worn around the shoulders, with the brand-name visible, to show their wealth. Sakoy then started to follow this fashion trend by putting less expensive towels around their shoulders. Kim expressed her attitude toward this fashion appropriated by sakoy that: "They try to make themselves look as cute and rich as the groups of higher-class girls but their cheap dress and towel make them look funny" (in-depth interview, 5 Febuary 2014). Some sakoy could afford brand name towels because they managed to buy them when 
a particular towel brand offered a discount, but by that time that items would already have become out-of-date for the higher-class groups. Some sakoy would also buy copied brand-named items or cheap ones from local markets.

Regarding the make-up style of sakoy, Mary commented that: "They don't have any principle of applying cosmetics on their faces. They just put those cheap and thick cosmetics on and try to look as white-skinned as possible" (in-depth interview, 5 February 2014). Since female youth who were categorized to be sakoy were often raised in rural working-class families, riding motorcycles rather than cars, it was true that they would be exposed to sunlight since they were children much more than girls who were born in more privileged circumstances. Therefore, most of them had darker skin, identifying them, in the eyes of the girl group, as lower-class. Sakoy perceived that wearing make-up could make them look whiter and more attractive; and their makeup style became one of the favorite topics for the members of the girl group to gossip about. Amy disparagingly described the way sakoy applied make-up 'white face, dark neck' (naa kaw kor dum). Some sakoy had such dark skin that the white foundation and powder they applied made their skin color look almost violet or dark blue. They also applied 'thick' cosmetics on other parts of their faces especially bright-red lipstick. Some of them applied 'Uthaitip', a Thai traditional liquid which is used for coloring drinking water, instead of lipstick. Apart from very low price, Uthaitip was another tactical practice among sakoy to evade school punishments for applying make-up in schools. Since Uthaitip was not considered a cosmetic by school authorities, carrying and applying Uthaitip on their lips instead of lipsticks was not considered as breaking the school regulations. Furthermore, most sakoy perceived red lips as indication of being healthy and attractive. Janet commented further that: "They always bring little mirrors and are putting on more cosmetics all the time. Why don't they know that when they put very thick white powder on their faces, the skin looks like bruised? It looks funny indeed!" (in-depth interview, 5 Febuary 2014).

Sakoy's taste for having a relationship with male was also often discussed among research participants. Sakoy were seen as being attracted to saap who were typically associated with aggression and delinquency, as well as membership of youth gangs.
The members of the girl-group saw saap were 'uncool' male working class youth who commute into the city in search of fun and trouble. Sakoy would ride motorcycles with their saap around Chiang Mai. They would meet especially at the back entrance of Cen and other nightlife zones where they could afford cheap food and (alcoholic) drinks at night time. While gossiping about saap and sakoy couples riding their motorcycles, Kim told the researcher to take a look carefully at some sakoy's necks and explained that: "Some sakoy have little bruises on their necks (roy dude tee kor, or love bites) to show off that they already had (sex with their) boyfriends because their boyfriend sucked up their necks. Sakoy have boyfriends to show that they are beautiful so they were attracted to saap. Those who don't have saap boyfriend and are still virgin (sing) will be ashamed (for not being attractive)" (in-depth interview, 5 February 2014).

Since being called 'sakoy' was unpleasant, female working class youth tried to rename themselves to be 'dek naew' (alternative style youth group), 'dek indy' and 'dek hip' (hipsters). However, the research participants and other higher-class youth would continuously use the disparaging term sakoy to maintain their higher status.

\section{Media Usage and Consumption Prac- tices Among Female Youth Who Were 'Hi-So Noi' (a Bit High-Class)}

Apart from spending their time at Kim's coffee shop at Cen, research participants mostly went to Ro during their leisure time. As mentioned thatRo was a shopping mall where mostly higher-class youth groups gathered. For example, B-Boys could be found there, rehearsing and showing their break-dance performances; skateboarders and other youth groups were there collecting various kinds of vehicles such as Vespa scooters and various models of car, and they would usually congregate and display their vehicles at the mall's parking spaces. In contrast to sakoy and saap, these higher-class youth groups required a certain amount of financial capital to be able to establish and maintain their social network and needed access to commercial commodities to purchase and signify their distinctive social identities.

In the mall building, especially on the upper floors, had a range of famous restaurants and coffee shops that were well- 
decorated, serving high-quality food and drinks. Despite the high prices they charged, these restaurants and coffee shops, especially those owned by celebrities, were filled with higher-class Chiang Mai teenagers. Prior to entering or eating, they often took pictures of the shops, food and drinks; and posted these in social media to show that they came to these relatively expensive places. The front area of these well-known restaurants and coffee shops was made of glass so that people who were passing by could take a look at the customers inside. Meanwhile, youth who were in those restaurants and coffee shops preferred sitting around the front area so that they could be gazed at by others.

Around the areas at $R o$ especially where higher-class youth groups gathered, saap and sakoy were rarely found since they did not feel a sense of belonging to these places. Once the researcher found a group of sakoy walking past the coffee shop while spending time with research participants. Those sakoy were stared at by girl group members; other higher-class groups also obviously gossiped and laughed which made the sakoy girls uncomfortable. Research participants commented that those sakoy did not belong there since they did not dress appropriately to be in line with the majority. They also could not afford the more expensive food and drinks around that area. If sakoy came to Ro, they mostly were found on the basement where certain cheaper local food and cloth shops were available to them. Mary told other group members a funny story about sakoy going to a high-class coffee shop. At one day she was studying and enjoying her coffee with her friends there when she saw a group of sakoy entering. They made a lot of noise trying to be at the center of attention; but it turned out that customers looked at them for all the wrong reason, since it was understood that customers should be quiet inside this coffee shop. While ordering, the sakoy girls could not correctly pronounce the names of the coffee types on offer. After they ordered, they immediately left the counter to find a place to sit but a waitress told them that they had to pay first and wait for their coffee at another counter. From this story, the group members were laughing for the way that those sakoy did not know the way to behave and order coffees in a high-class coffee shop.

Regarding consumption practices among research participants at shopping malls especially at Ro, although it was the place for the higher-class groups, it was noticed that the girl group members rarely bought items while shopping there. Apart from spending time in well-known restaurants and coffee shops, they mostly walked around the mall to do window-shopping. Rose explained the meaning of her window shopping that: "I don't come for buying anything in a mall. It is too expensive. I'm not stingy. I spend money wisely. We come to check out the latest fashion styles and then I try to mix and match what I've got at home later" (in-depth interview, 5 Febuary 2014). Other research participants described their shopping and dressing practices in similar ways. Once in a while, they would decide to buy expensive major items such as shoes, handbags, cloths and cosmetics at the mall; but minor things, such as hair and fashion accessories, they could find in other (cheaper) community malls around Chiang Mai. Then they mixed and matched expensive major items bought from shopping malls with other minor items into their own style, which they learned from various sources, including from doing window shopping at shopping malls. Janet elaborated more that: "Firstly we have to figure out the main items of that day, such as shoes, handbags, skirts, or shirts. Then we mix and match other items and make-up that get along well with the particular color and style of the main items of that day. So we can end up with our own outfit" (in-depth interview, 5 Febuary 2014). Other research participants added that they believed in minimalism, meaning that they wore fewer accessories so that when they considered any item did not get along well with others, they took it off and changed it to something else. Moreover, the group members often exchanged clothes and accessories among themselves, so that they did not have to buy new items very often. Some research participants, especially Cindy, posted various pictures of her used clothes on her Facebook page, asking to exchange them with other Facebook friends who belonged to the same higher-class group. Thus, clothes and fashion commodities were circulated among higher-class female youth groups to mix and match into their own style.

Besides window shopping, Internet idols who produced video clips or Internet TV programs to review and tutor various styles of dressing and make-up also severed as an important inspiration for the girl group members to appropriate new fashion and make-up styles. Momay Paplern (Being Amused with Momay) was one of the independent Internet program hosted by 
Momay, a Thai singer who was well-known a decade ago and then became an Internet idol for her Internet make-up tutorial video clips posted in SpokeDark Internet channel and Youtube. Some of her make-up tutorial clips hit more than million views. Most research participants were huge fans of Momay Paplern and followed almost every clip of her. Nancy expressed her admiration of Momay that: "I watched almost every of her make-up tutorial clips, especially the one about make-up for pretty. It was very useful for me. I learned a lot about make-up tricks from her" (in-depth interview, 5 February 2014). The main reason that research participants followed Momay was that she tutored and provided various tricks for make-up that was not 'low-class.' Momay always kept up her make-up tutorial program details by updating it with both national and international make-up trends from celebrities and events at that particular period of time. Lisa also added that, apart from her cheerful personality and sense of humor while hosting the program, the products that Momay reviewed in her program were not the kind of cheap items that were used among sakoy. Momay reviewed cosmetic products with high quality and affordable prices. Momay's make-up tricks also emphasized various themes that were appropriate for their particular social context, such as make-up for hanging out at night, going to a wedding, going to classes, or even joining a Halloween party; each of which required different styles and tricks. Nancy concluded the main idea of this program, from her perspective, was that: "I leaned from her that the most important is healthy-looking skin. Like I have a tan skin; no need for me to put thick foundations and powder to make me over-whitened. I should apply cosmetics that are compatible with my original skin color. Every time I use make-up I should come up with a clear concept in my mind of how I'm going to dress and where I'm going to go; so that I can come up with particular style of my make-up for that day. Unlike sakoy, they don't have any concept for the way they dress and apply make-up so they look tasteless and funny. Another thing is that some of Mamay Paplern clips are in English so that sakoy will never understand (laughs). "Vicki said that sakoy always follow dressing and make-up trends from celebrities without realizing that everyone had her own unique face outline which was different from person to person. She said that sakoy only tried to imitate intending to look exactly like those celebrities by putting cosmetics on their face as thickly as possible. Vicki kept in mind what Momay said in her program: "We can't exactly imitate the ways those celebrates make-up and dress, but we can appropriate their styles into our own" (in-depth interview, 5 Febuary 2014).

Once the researcher accompanied Rose to do shopping at the cosmetic counters at Ro prior to going out with other girl group members that night. Rose asked the sales persons for certain cosmetic items. Then she asked them to demonstrate several cosmetic products on her face and ended up buying just a few of them. After leaving, Rose revealed that it was a trick she used to obtain free make-up before going out. It was considered a win-win situation for Rose that while those salespersons could sale some of their products, she could learn more make-up techniques from them as well as obtain free make-up.

The girl group members explained that the principles that distinguished them from sakoy was that, apart from the latter's lack of financial capital, sakoy had also a lack of taste through the ways they tried to dress and make-up. For example, Jill posted a picture taken in a mall of a sakoy who was wearing a shockingly pink shirt and black pants, which was considered to be bad taste, in the online secret group. Jill explained that while a sakoy in the picture was on a motorcycle (identifying her as lower-class) someone who was in a car (i.e. belonging to a higher class) yelled at her that she had bad taste of dress. Jill then posted a sarcastic face icon.

\section{Negotiating Sexual Selves Through Media Usage and Consumption Prac- tices in Shopping Malls}

As mentioned above, Ro served as a place where the girl group members would spend their times when they wanted to skip classes while they were in high school. Nancy was one of the group members who used to get caught by authorities for this. In a result, she was brought back to the school; her behavioral scores were decreased and her parents were ultimately informed. Therefore, Nancy learned from her experience that authorities would approach teenagers who went to shopping malls by searching for any sign that could identify that they were students of a particular school. As students in Chiang Mai schools are required to use items that were exclusively designed by each school, such as a particular type or color of 
jacket, backpack, etc, while skipping classes and spending times at places outside school during school hours, the girl group members would usually prepare another set of clothes and a non-identifiable bag, so that they could change and conceal their status of high school students. Nancy stated further that being female helped too: "Most students [who are skipping class] who are caught are boys because they have their short hair which is obvious. Girls have long hair so we just make a little hairdo, put some make-up, and change the ways we dress so we can look older" (indepth interview, 5 Febuary 2014).

While spending time in shopping malls, the girl group members also warned each other not to go online to their social media pages, and especially not to post any status update or check-in on their Facebook accounts, as this would identify them as being outside the school area. Jill shared that her friends were tracked and caught by school authorities because they had left their Facebook accounts online while they skipped classes and spent time outside the school during school hours. This story corresponded with the data collected from the teachers:

"When I'm at my office, I also track students from Facebook. I could track the location where they are and I could drag them back to the school... I'm not smart but I can follow them wherever they are. I have the expanded networks, even with traffic policemen. I stay at this room but I can call my networks to drag those students back to the school. I have a lot of experiences on this" (in-depth interview, 12 November 2013)

Homosexual relationships among female students were another tactic to express their sexual subjectivity in ways that shielded them from the eyes of school authorities in shopping malls. Female homosexual relationships were also widely expressed in shopping malls in Chiang Mai, especially at Ro, as a transcription from a topic posted in a popular website mentioned earlier. Around the mall territory, especially on the upper floors where higherclass youth would gather, female youth were found expressing intimacy with other girls widely, particularly during the weekends and public holidays. Like the situation at school, research participants stated that homosexual relationships in shopping malls, especially among females, had never been reported by authorities. In contrast, heterosexual relationships were likely to be monitored. In Ro, female homosexual couples could make do more general spaces since toms were able to socialize in the same pattern as other women. As research participants mentioned that the some of the benefits of having female homosexual relationships were that women understood each other's needs better and they could go out together without any suspicion from parents and authorities, for that reason female same-sex couples could be usually seen accompanying each other in shopping malls. While they were doing shopping and walking together in the mall, some of them were found holding each other's hands. Tom was the one who took care of her lover's handbag and shopping bags to conform the expectations that would be placed on a masculine lover. They could go together everywhere, even to restrooms and fitting rooms. Restaurants and coffee shops that were mostly designed with large windows in the front, allowing people passing by to gaze at the customers and at the situation inside, female homosexual couples were comfortable touching, hugging, and expressing their affection in front of the public while people also seemed comfortable seeing them expressing intimacy to each other at these places.

Various spaces and activities in Ro were also tactically utilized by female youth to gain a certain level of sexual freedom. Many couples went to watch movies in order to spend time alone together. Erotic or romantic scenes, darkness in a theater, and special seats where the arm-rest could be raised, exclusively designed for couples, conveniently located at the back-rows were supportive factors for them to express intimacy in various forms, range from toughing, holding hands, hugging or kissing. Research participants who had boyfriends or girlfriends said that they chose to watch movies especially later at night when there were not too many people in the cinema. If they did not book special seats at the back rows (which were more expensive), they waited until the movie was about to start and bought tickets in seats that were far away from other customers (unlike in Western countries, in Thai cinemas the customers can see which seats are occupied and which are still available and pick their own seats). During the fieldwork, there were also some leaked video clips about young people having sex in the cinema, which was caught by surveillance cameras; these clips were widely shared in social media.

Some coffee shops and restaurants were also attracting young romantic couples 
by having certain tables located at a corner or behind partitions that could thus be used as private spaces to spend their time together. Various activities such as games booths, karaoke booths, and photo booths were also tactically used as opportunities for them to get close to each other in public spheres.

\section{Conclusions}

Throughout this paper, everyday life cultural and sexual practices among female youth in shopping malls in modern Thai society were closely examined. Applying Bourdieu's idea of 'cultural capital' (ibid), this paper revealed that female youth who were research participants actively identified themselves to be 'higher-class' and have 'better taste,' comparing to the lower-class female youth group, which they referred to as sakoy. This superiority was instilled through various forms of space utilization and cultural commodities consumption - such as spending time in high-class shopping malls, coffee shops, restaurants, and nightclubs; and displaying their good taste through fashion and dressing. Within the realms of shopping malls were also actively made do among female youth to negotiate and contest various dominating powers, especially via school and the state social order. The female youth prepared another set of clothes and a non-identifiable bag to conceal their high school student status; they also turned off their social media to evade of being tracked and caught by school authorities while skipping classes and spending times at places outside school during school hours. Homosexual relationships among young women in shopping malls were widely found. Young lovers usually utilized spaces in cinemas, coffee shops, restaurants, games booths, karaoke booths, and photo booths in order to 'spend time alone' together. These media usage and consumption practices could serve the interests of the female youth to achieve a productive pleasure by utilizing them in alternative ways - to send a message of evasion or even resistance that they were independent agncies and not conformists to mainstream standards (Fiske, ibid).

The results of this study have shown that female youth in modern society have their own ability to negotiate, appropriate, transform, or reproduce their media usage, consumption practices, as well as their gendered and sexual subjectivities to meet their own goals, as reflected through their cultural and sexual practices in daily life - the subtle ways in which ordinary people "poach" the property of others and adapt it to their own ends is a central feature of everyday life (de Certeau, 1988). In the meantime, while the social controlling mechanisms play a critical role in the process of sexual and gender socialization, female youth are also able to compromise and resist this for their own ends. Female youth's cultural and sexual practices in everyday life presented in this paper therefore become a significant sphere where the female youth 'actors' maintain their ability to define who they are in a modern society.

\section{References}

Bourdieu, P. (1984). Distinction: A Social Critique of the Judgement of Taste. London: Routledge.

Cohen, A. (2009). Dek Inter and the 'Other': Northern Thai Youth Subculture in Urban Chiang Mai. Journal of Social Issues in Southeast Asia, 24(2), 161-185.

de Certeau, M. (1988). The Practice of Everyday Life. Berkeley, California: University of California Press, Ltd.

Fiske, J. (1989). Understanding Popular Culture. London: Unwin Hyman.

Fongkaew, W., Wongpanarak, N., Fongkaew, K., \& Lertmallikaporn, S. (2007). A Study of Sexual Identity Among Adolescents. Chiang Mai: Nopburee.

Khosravi, S. (2008). Young and Defiant in Tehran. Philadephia: University of Pennsyvania Press.

Michinobu, R. (2005). Lives in Transition: The Influence of Northern Thailand's Economic and Cultural Change on Young Factory Women's Sexual Behavior and HIV Risk. Nakornpathom: Center for Health Policy Studies, Faculty of Social Science and Humantities, Mahidol University, Salaya Campus.

Wilson, A. (2004). The Intimate Economics of Bangkok: Tomboys, Tycoons, and Avon Ladies in the Global City. Berkeley: University of California Press. 